\title{
DIAGNÓSTICO DAS MANIFESTAÇÕES PATOLÓGICAS IDENTIFICADAS NAS EDIFICAÇÕES DO PARQUE DE USO MÚLTIPLO (PUM)
}

\author{
Juliana Furtado Arrobas Martins, Cesar Fabiano Fioriti \\ Universidade Estadual Paulista - UNESP. Curso de Arquitetura e Urbanismo, Presidente Prudente - SP. E-mail: \\ juarrobas@hotmail.com
}

\section{RESUMO}

Este trabalho trata-se de um estudo de caso realizado nas edificações que constituem o Parque de Uso Múltiplo (PUM), sendo edificações públicas pertencentes ao município de Presidente Prudente, onde através de inspeção visual foram identificadas as manifestações patológicas existentes nos sistemas estruturais em aço. Para isso foi realizada a análise dos aspectos gerais das anomalias, com o objetivo de identificar os danos encontrados. As manifestações detectadas que ocorreram com maior incidência foram: corrosão nas bases dos pilares, apoio incorreto da treliça sobre o pilar, desalinhamento dos pontos de ligações das treliças, desalinhamento dos pontos de ligações entre treliças e pilares, além de corrosão dos perfis das treliças e dos contraventamentos. As informações obtidas e fornecidas com a elaboração deste estudo têm como objetivo propiciar conhecimento e melhoras nos níveis atuais de durabilidade e vida útil das estruturas em aço.

Palavras-chave: Edificações públicas; Manifestações patológicas; Sistemas estruturais, Estruturas em aço.

\section{DIAGNOSIS OF PATHOLOGICAL MANIFESTATIONS IDENTIFIED IN BUILDINGS OF THE PARQUE DE USO MÚLTIPLO (PUM)}

\begin{abstract}
This work is a case study performed in buildings that constitute the Parque de Uso Múltiplo (PUM), and these public buildings belong to the municipality of Presidente Prudente, where through visual inspections were identified the pathological manifestations in structural systems in steel. For this work were performed the analysis of the general aspects of the anomalies in order to identify the damage that were found. The detected manifestations that occurred with the highest incidence were: corrosion on the bases of the pillars, incorrect support of the trusses on the pillar, misalignment of the connections points between trusses, misalignment of the connections points between trusses and pillars, and corrosion of trusses and bracing. The information obtained and supplied with the preparation of this study are intended to provide knowledge and improvements in current levels of durability and service life of steel structures.
\end{abstract}

Keywords: Public building; Pathological manifestations; Structural systems, Steel structure. 


\section{INTRODUÇÃO}

Desde os primórdios da civilização o homem vem desenvolvendo técnicas, materiais e métodos, consolidando assim cada vez mais a tecnologia da construção. As Inovações e a rapidez de execução acarretaram na necessidade de se desenvolver o conhecimento relacionado às estruturas e aos materiais, a fim de proporcionar o avanço das construções. Porém, ainda que o investimento em tecnologias relacionadas a essas construções cresceu e evoluiu notoriamente, ainda assim, existem sérias limitações e inevitáveis falhas que acabam por prejudicar o desempenho de algumas estruturas.

Esses fatores conduzem ao surgimento de patologias, que podem ser entendidas como a deterioração dos materiais que compõe o sistema estrutural, onde cada material reage de forma particular aos agentes externos e internos, sendo a velocidade de deterioração diferente um do outro (SOUZA e RIPPER, 1998).

Os problemas de deterioração da estrutura e de seus materiais componentes decorrem, em grande parte, de um projeto inadequado e de uma execução mal cuidada, deficiências que ainda se constata serem comuns, provocando a ocorrência de falhas que, fatalmente, resultam na necessidade de recuperação ou de reforço da estrutura (ou até mesmo, em casos extremos, de demolição) (SOUZA e RIPPER, 1998).

O uso do ferro e do aço está presente na história da humanidade desde a Antiguidade, passando a serem utilizados como materiais de construção a partir dos séculos XVIII e XIX e, juntamente com o desenvolvimento tecnológico que surgia, transformaram toda uma época através da Revolução Industrial (BANDEIRA, 2008).

No Brasil, a partir da segunda metade do século XIX, a burguesia emergente voltava-se para o consumo dos produtos europeus, e desta maneira, edifícios metálicos inteiros foram comprados, desde teatros, mercados, até estações ferroviárias (COSTA, 2001).

Portanto, somente no final da década de 1950 e na década de 1960, a estrutura de aço começa a ser utilizada no nosso país. Nesta época, a estrutura de aço era usada basicamente como um esqueleto interno do edifício, e sua forma e seu sistema estrutural eram pouco trabalhados (MARINGONI, 2004).

O uso da estrutura metálica no Brasil ainda não é tão intenso se comparado com outros países mais desenvolvidos na área da construção. A falta de conhecimento do material pelos profissionais de engenharia e arquitetura, originada de uma formação enraizada no uso do concreto armado, contribui para a não utilização do aço nas estruturas, como também para erros de cálculos, má concepções de projetos, escolha de perfis ou chapas de espessura inadequada, ou 
ainda no uso de tipos de aço com resistência diferentes das consideradas no projeto, gerando assim o aparecimento de manifestações patológicas.

Com isso, este trabalho trata-se de um estudo de caso realizado nas edificações que constituem o Parque de uso múltiplo (PUM), onde através de inspeção visual foram identificadas e analisadas as manifestações patológicas existentes nos sistemas estruturais em aço da edificação.

\section{METODOLOGIA}

O método escolhido para a formulação do trabalho foi o de estudo de caso, visto que este método é considerado altamente rico sob o ponto de vista didático. Dessa forma, o estudo de caso foi a alternativa expositiva escolhida para apresentar o equacionamento das soluções dos conflitos que o envolvem.

Foram necessárias quatro etapas para a realização do trabalho, as quais são apresentadas de forma esquemática na Figura1.

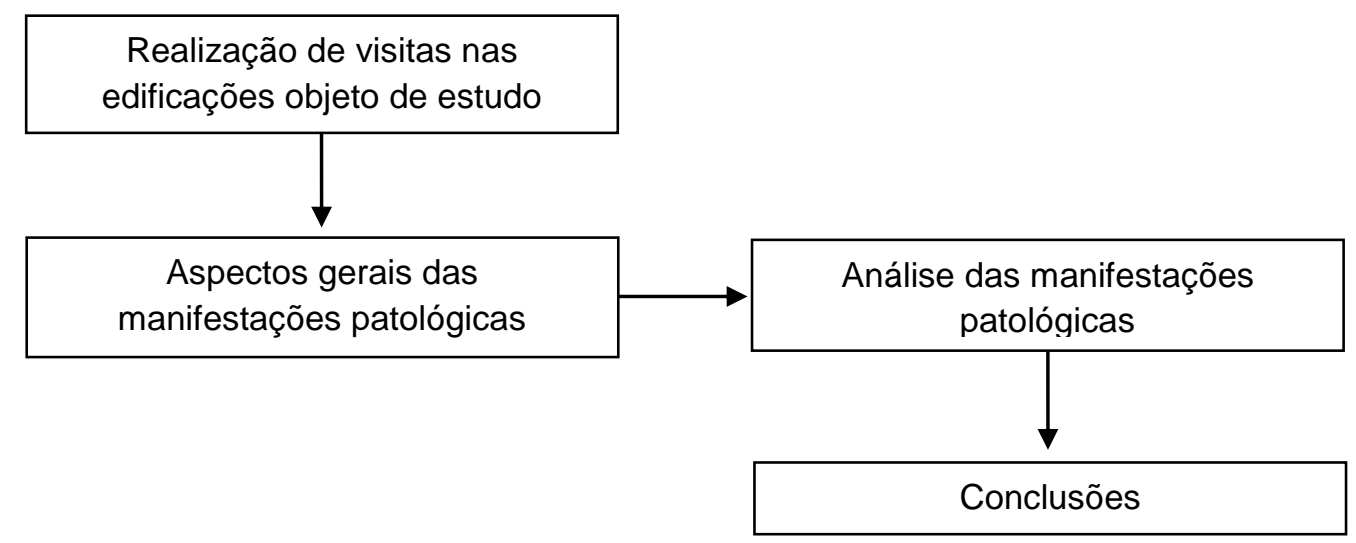

Figura 1. Esquema das etapas executadas no desenvolvimento do trabalho.

Conforme as etapas utilizadas no desenvolvimento deste trabalho, foi possível percorrer um caminho curto e simplificado, visto que não foram utilizadas etapas de exames adicionais e de execução das terapias, mesmo porque não é objetivo deste trabalho realizar exames laboratoriais sobre as propriedades físicas e químicas dos materiais constituintes do estudo de caso. Assim:

- 1a etapa: realização de visitas in loco nas edificações que constituem o PUM, para identificação e registro fotográfico das manifestações patológicas existentes nos sistemas estruturais em aço;

- 2a etapa: descrição dos aspectos gerais das manifestações patológicas encontradas nos sistemas estruturais em aço, com o objetivo de identificar as anomalias existentes;

- 3a etapa: análise das manifestações patológicas encontrada nos sistemas estruturais aço;

- 4a etapa: conclusões. 
Destaca-se que não foi objetivo deste trabalho entrar no mérito da qualificação e da atuação dos profissionais e empresas que participaram dos projetos e execução das obras analisadas, tendo como único foco o levantamento das manifestações patológicas que podem vir a ocorrer em sistemas estruturais estruturados em aço e a importância de evitá-las.

\section{RESULTADOS}

\section{Escolha do objeto e localização}

O critério de escolha do PUM partiu do quesito estrutural, ou seja, a definição do aço como material constituinte do sistema estrutural e ter suas estruturas aparentes. Pois nestas condições seria possível identificar e analisar, a partir das visitas a campo e fotografias digitais, as eventuais manifestações patológicas.

Localizado na Avenida Coronel José Soares Marcondes, nำ 1.842, no centro de Presidente Prudente, o PUM foi uma obra realizada pela prefeitura em benefício à população, sendo inaugurado em 15 de julho de 1980.

Atualmente, o PUM é composto por um conjunto de três edificações (Figura 2), porém, estas não foram executadas simultaneamente, sendo que na inauguração deste parque existia somente uma única quadra poliesportiva. Em maio de 2010 foram construídas mais duas quadras poliesportivas, além de salas para uso múltiplo e salas administrativas. Por fim, em julho de 2011 foi inaugurada a terceira edificação composta por duas canchas de bocha, constituindo as edificações do PUM.

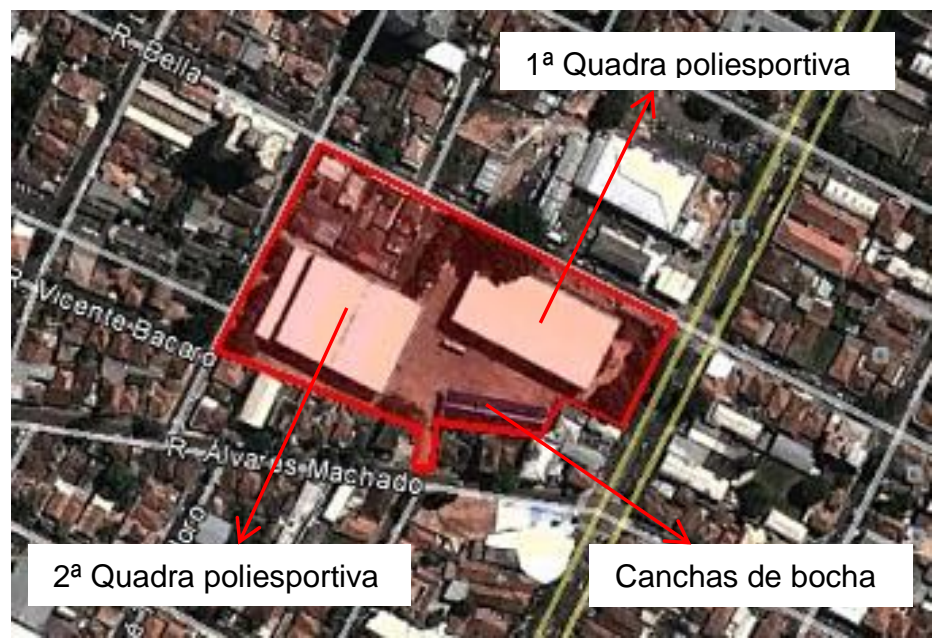

Figura 2. Edificações que constituem o PUM.

Fonte: Google Maps, 2014 - editado. 


\section{Aspectos gerais das manifestações patológicas identificadas}

As manifestações patológicas mais relevantes que foram identificadas no PUM são: corrosão nas bases dos pilares (Figura 3; Quadro 1), apoio incorreto da treliça sobre o pilar (Figura 4; Quadro 2), desalinhamento dos pontos de ligações das treliças (Figura 5; Quadro 3), desalinhamento dos pontos de ligações entre treliças e pilares (Figura 6; Quadro 4) e corrosão dos perfis das treliças e dos contraventamentos (Figura 7; Quadro 5), sendo elas apresentadas a seguir:

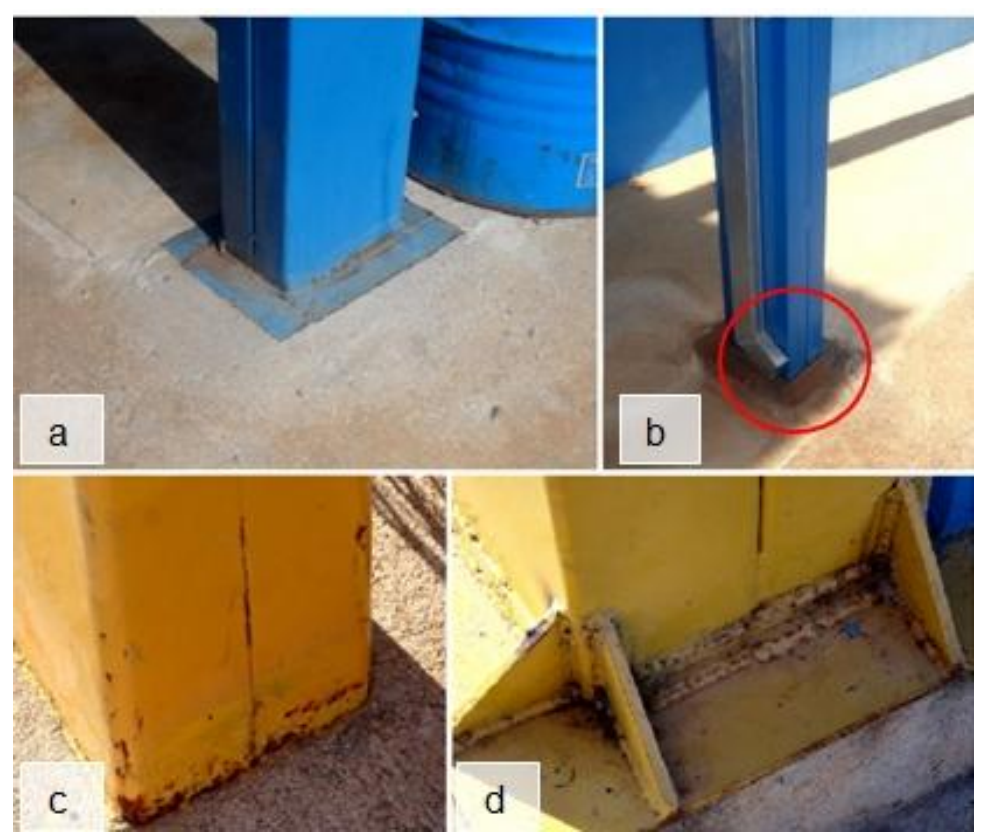

Figura 3. Corrosão nas bases dos pilares distintos.

Quadro 1. Aspectos gerais das bases dos pilares distintos.

- Base dos pilares no mesmo nível do piso (fig. 3a, fig. 3b, fig. 3c);

- Corrosão nos cordões de solda entre chapa de topo e pilar (fig. 3a, fig. 3b, fig. 3d);

- Perda de parte do acabamento (pintura);

- Manchas marrom-avermelhadas, devido ao processo existente de corrosão nas bases;

- Presença de duto de água pluvial com saída direta na chapa de topo do pilar. 


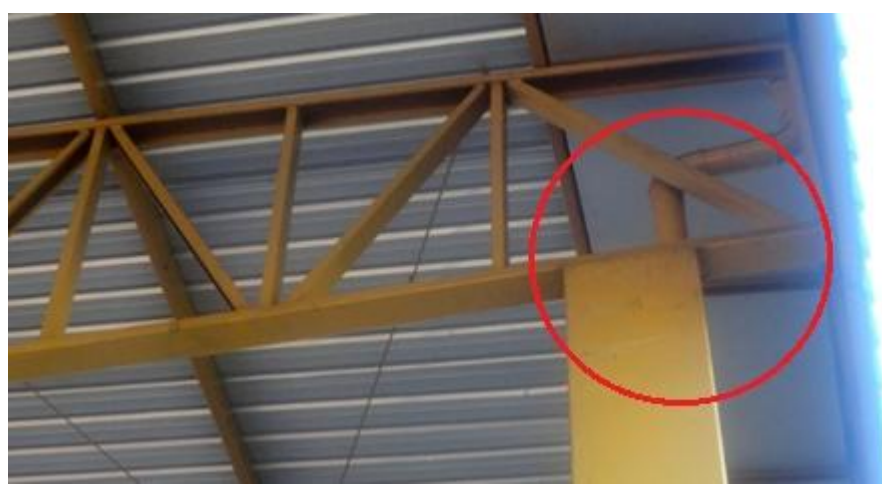

Figura 4 Apoio incorreto da treliça sobre o pilar.

Quadro 2 Aspectos gerais dos apoios incorretos das treliças sobre os pilares.

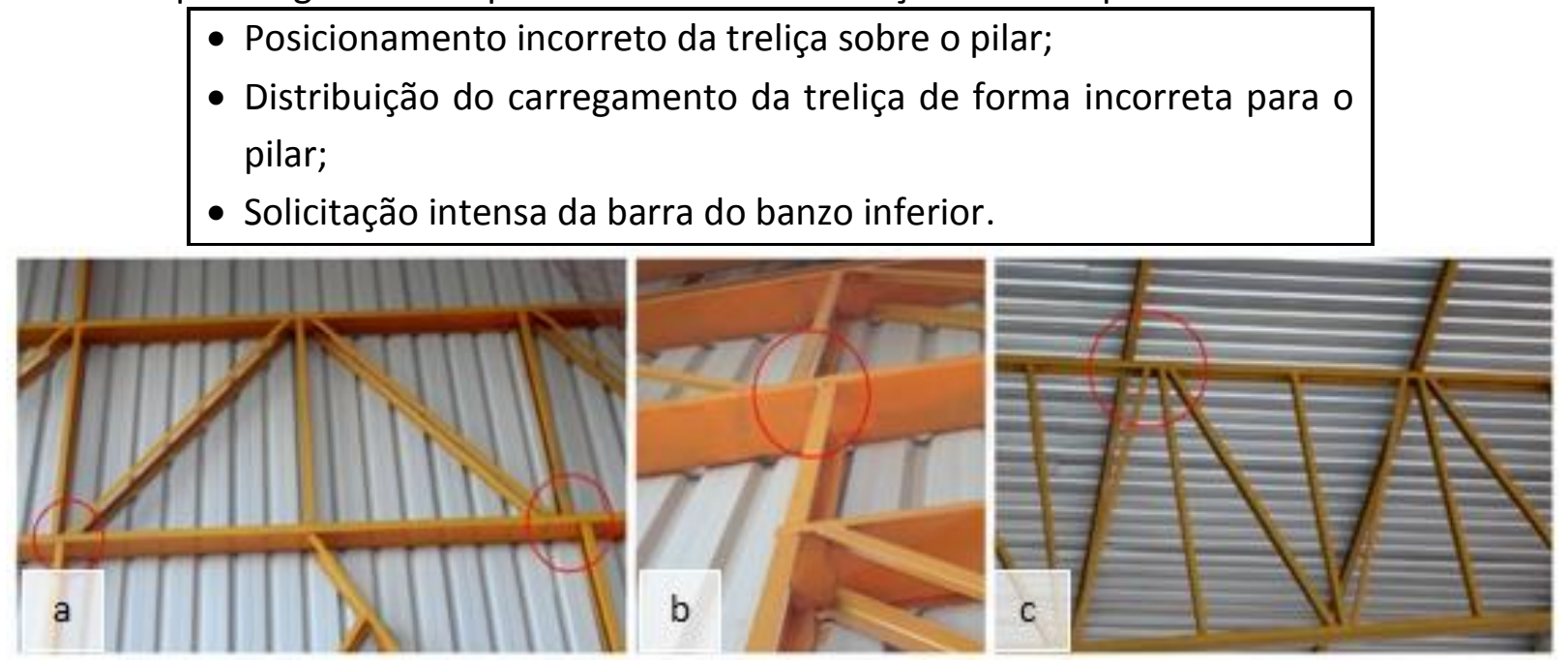

Figura 5. Desalinhamentos dos pontos de ligações das treliças.

Quadro 3. Aspectos gerais dos desalinhamentos das ligações das treliças.

- Desalinhamento dos montantes (fig. 5a, fig. 5b);

- Terça posicionada fora do nó (fig. 5c);

- Solicitação intensa da barra do banzo superior (fig. 5c);

- Prejudica a estética da edificação.
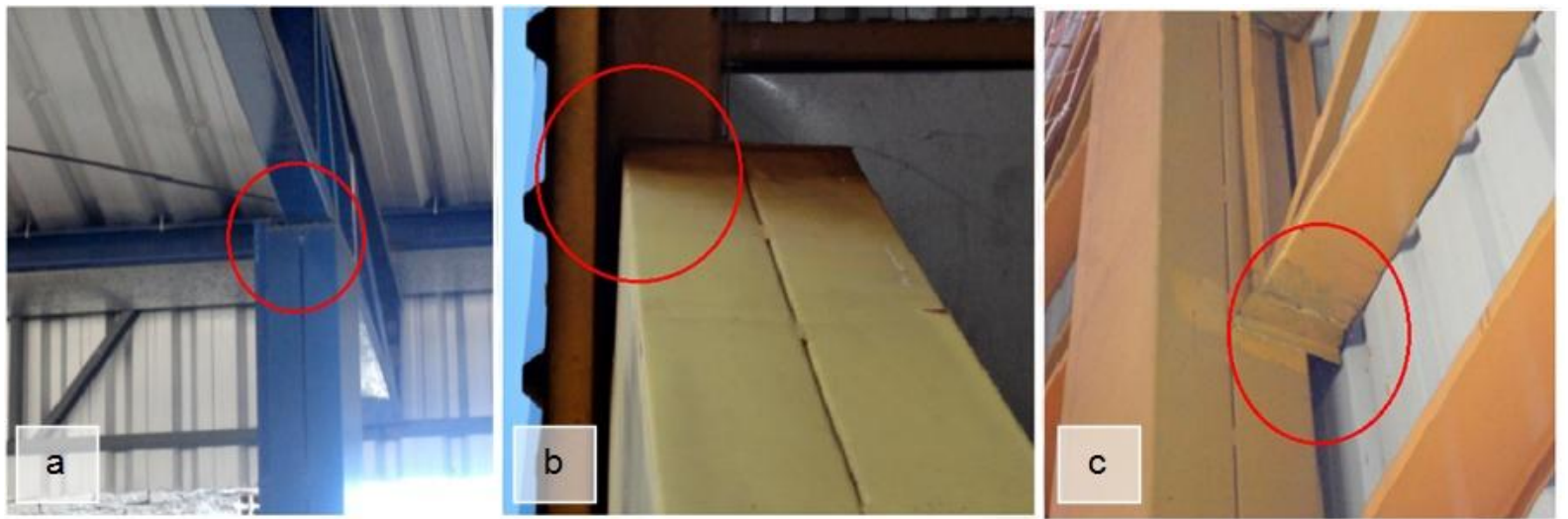

Figura 6. Desalinhamentos dos pontos de ligações entre treliças e pilares 
Quadro 4. Aspectos gerais dos desalinhamentos das ligações entre treliças e pilares.

- Treliças apoiadas fora do eixo do pilar (fig. 6a, fig. 6b);

- Trecho da treliça apoiado fora do pilar (fig. 6b);

- Treliça e pilar: trecho fora da ligação (fig. 6c);

- Prejudica a estética da edificação.
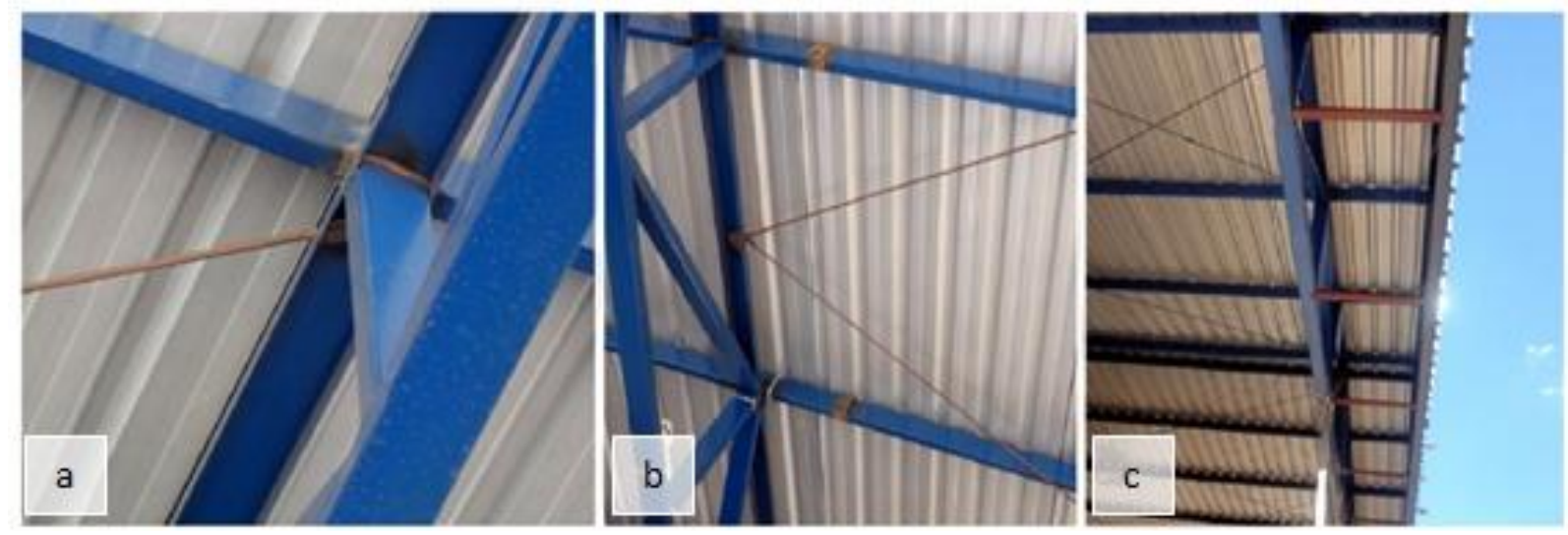

Figura 7. Corrosão dos perfis das treliças e dos contraventamentos.

Quadro 5. Aspectos gerais das treliças e contraventamentos que apresentam corrosão.

- Falta de acabamento (pintura) nos pontos de solda;

- Coloração marrom-avermelhada em perfis, devido à corrosão;

- Coloração marrom-avermelhada em cordões e pontos de soldas, devido à corrosão;

- Perda de massa dos contraventamentos;

- Perda de massa dos perfis;

- Presença de corrosão uniforme e por pontos;

- Prejudica a estética da edificação.

\section{DISCUSSÃO}

Com base no estudo realizado é possível elaborar uma análise dos resultados obtidos a partir de cada manifestação patológica detectada A corrosão na base dos pilares apresentou pontos de maior e menor intensidade de corrosão, sendo facilmente detectados nas juntas e cantos das bases, ocorrendo, provavelmente, por acúmulo de água e poeira. Devido ao fato da maioria dos pilares terem suas bases ao nível do piso, estes ficam submetidos ao contato direto com a água, e por não possuírem nenhum tipo de elevação por outro material mais resistente à corrosão acabam apresentando esse tipo de anomalia mais facilmente, acarretando na perda de material, e consequente redução da capacidade estrutural da peça.

O apoio incorreto da treliça sobre o pilar ocorreu de forma repetida em todos os apoios das treliças sobre os pilares, sendo este apoio realizado nas barras dos banzos inferiores das treliças, e não nos nós (forma correta de realizar este tipo de apoio), prejudicando o correto 
funcionamento da estrutura, podendo assim, acarretar no desenvolvimento de esforços de flexão nas barras dos banzos inferiores, prejudicando o funcionamento adequado das treliças.

O desalinhamento nas ligações das treliças também ocorreu de forma repetida apresentando vários erros de posicionamento de uma treliça em relação à outra, em que os pontos de ligação não estão feitos de forma correta, apresentando desalinhamento dos montantes, além de terças posicionadas fora dos nós, acarretando na solicitação intensa da barra do banzo superior, prejudicando o funcionamento adequado da estrutura. Da mesma forma que na anomalia anteriormente citada, o desalinhamento nas ligações entre treliça e pilar ocorreu mais de uma vez e apresentou erros de posicionamento, de forma que as treliças estão apoiadas fora do eixo do pilar, prejudicando, também, o funcionamento adequado da estrutura.

Por fim, a corrosão foi a manifestação patológica detectada em todos os elementos estruturais que compõem as edificações analisadas, apresentando vários pontos de corrosão, sendo este o fenômeno patológico de maior conhecimento e percepção dos usuários, que pode ocorrer principalmente devido ao acúmulo de água, poeira, e ação dos agentes agressivos da própria atmosfera, ou ainda devido a uma manutenção precária e falta de reparos na pintura, que acarretam numa diminuição da proteção do material, que se torna suscetível aos processos de corrosão, gerando a perda de seção do elemento, resultando assim, na redução da capacidade estrutural da estrutura.

\section{CONCLUSÃO}

As análises e resultados obtidos foram decorrentes de trabalhos de campo realizados nas edificações que constituem o PUM, examinando os elementos estruturais que as compõem. Ressalta-se que é de grande relevância as informações obtidas e fornecidas com a elaboração deste estudo, objetivando propiciar conhecimento e melhoras nos níveis atuais de durabilidade e vida útil das estruturas em aço.

Através deste estudo e das análises realizadas, é possível afirmar que muitas das manifestações patológicas detectadas poderiam ter sido minimizadas, e até mesmo evitadas, caso houvesse maior controle das etapas do processo construtivo, e que ao serem associadas a uma efetiva manutenção das estruturas de aço, poderiam proporcionar maior qualidade e vida útil aos elementos estruturais.

Desta forma, anseia-se que esse trabalho possa expor a projetistas, construtores e usuários, os problemas patológicos que podem ocorrer em estruturas de aço quando estas não recebem os cuidados e procedimentos necessários para seu funcionamento ideal, e com isso, 
proporcionar maior atenção e consciência por parte desses, a fim de que se atentem cada vez mais para as precauções e especificações de procedimentos a serem tomadas para a construção, como também para a utilização de uma estrutura.

\section{REFERÊNCIAS}

BANDEIRA. A. A. C. Análise do uso de estruturas de aço em edificações habitacionais de interesse social. Monografia - Especialização em Construção Civil - Universidade Federal de Minas Gerais, Belo Horizonte, 2008.

SANTOS, T. S. Patologias em edificações com estruturas em aço - estudo de caso em presidente prudente. Relatório de Iniciação Científica FAPESP, Presidente Prudente, 2013.

MARINGONI, H. M. Princípios de arquitetura em aço. Belo Horizonte: Gerdau Açominas, 2004.

SOUZA, V. C. M. de, RIPPER, T. Patologia, recuperação e reforço de estruturas de concreto. São Paulo: PINI, 1998. 